\title{
Use of Electrofacies, Spectral Decomposition and Neural Network seismic inversion technique to analyze a fluvial channel system, Browse Basin, Western Australia
}

Diego Vasquez Perez ${ }^{*}$ and Lilik Hardanto, Emerson Automation Solutions.

Copyright 2019, SBGf - Sociedade Brasileira de Geofísica

This paper was prepared for presentation during the $16^{\text {th }}$ International Congress of the Brazilian Geophysical Society held in Rio de Janeiro, Brazil, 19-22 August 2019.

Contents of this paper were reviewed by the Technical Committee of the $16^{\text {th }}$ International Congress of the Brazilian Geophysical Society and do not necessarily represent any position of the SBGf, its officers or members. Electronic reproduction or storage of any part of this paper for commercial purposes without the written consent of the Brazilian Geophysical Society is prohibited.

\section{Abstract}

Electrofacies analysis allows taking advantage of different electrical measurements, to describe rocks formed under specific geological conditions that reflect a particular process or deposition environment. However, as they are bounded to the wells themselves, investigating lateral changes can prove to be challenging, especially on fluvial environments as well information lacks a continuous spatial coverage.

In order to overcome this limitation Electrofacies information was used to guide and validate the results of a Neural Network seismic inversion technique applied on a section of the Browse Basin in Western Australia.

Artificial Neural Networks (NN) were used to invert poststack seismic data into the petrophysical attributes, and validate against the information at the well. seismic data and a reference horizon constraints are used as input and petrophysical attribute data (GR and Resistivity well logs) are used as desired output data to train the Neural Network. The trained Neural Network is used to predict the petrophysical attributes by using the seismic data. Spectral decomposition is a non-unique process for which various techniques exist and newer modified techniques are being discovered.

Spectral decomposition of seismic data and NN seismic inversion was used as a tool for stratigraphic analysis, helping to identify and delineate channel systems in the Browse Basin, Western Australia, for reducing the likelihood of dry well drilling. In this paper, seismic facies mapping uses the power of Neural Networks to classify subtle changes in waveform using horizon surface and petrophysical log relationship between seismic traces from 3D seismic data. The resulting maps represent a geological system rather than a single seismic attribute which can then be used to better understand the reservoir distribution, helped by spectral decomposition technique for imaging and mapping bed thickness, geologic discontinuities and channel delineation in puffin formation based on distinctively channels (oil bearing) that were delineated in the area, by wells that have been drilled in this area, and some stratigraphic features identified.

\section{Introduction}

Since the stratigraphy resonates at wavelengths dependent on the bedding thickness, the interpreter can image not only subtle thickness variations and discontinuities, but also accurately predict bedding thickness quantitatively (Partyka and Gridley, 1999). In addition, since the high-frequency response of a reflector can be attenuated by the presence of compressible fluids, spectral decomposition can also assist in the direct detection of hydrocarbons (Castagna, 2003). Volume visualization and interpretation can enhance the interpretation, hence helping to significantly reduce exploration risks.

Qualitative seismic facies, time structure, isochrone, and quantitative seismic attributes, neural network seismic inversion were used as additional means to characterize seismic units and individual surfaces. These tools capture depositional variability through the stratigraphic evolution of the system.

The Browse Basin (Figure 1) is part of the Westralian Superbasin, located on the Australian North West Shelf (NWS). This Superbasin also includes the Carnarvon, Canning, and Bonaparte Basins (Stephenson and Cadman, 1994).

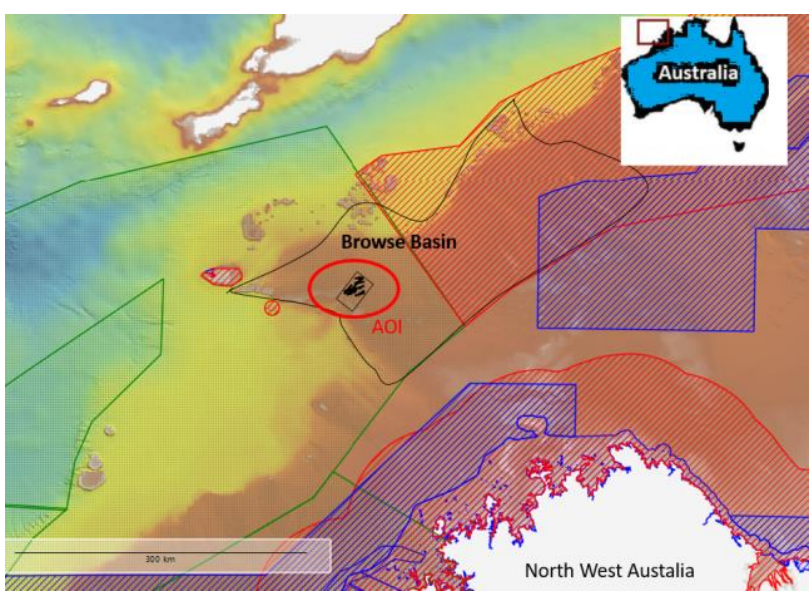

Figure 1 - Location of Browser Basin on the North West of Australia.

During a period of little tectonic activity during the Cretaceous, an important amount siliciclastic (fluviodeltaic), passive margin sediments were accumulated in the Browse Basin, transitioning to carbonate dominated in the Eocene (Apthorpe, 1988; Stephenson and Cadman, 1994). During the Paleocene - Eocene, more favorable conditions for a carbonate system are encounter due to migration north of the NWS of Australia (McGowran et al., 2004). 
Minor structural deformation and basement subsidence started during the late Oligocene, due to the collision of the Australian plate with the Banda Arc, and development of the Timor Through (Baillie et al., 1994; Kennard et al., 2003).

During the Oligocene-Miocene the Australian NWS migrates farther north (McGowran et al., 2004), while during the Early to Middle Miocene a fall of the eustatic sea level, forces the transition to a tropical photozoan rimmed shelf (Reuning et al., 2009). Finally a sea level rise during the Early Tortonian, associated with the collision of the Australian Plate with the Banda Arc, drowned the Browse Basin's Miocene barrier reefs, atolls and patch reefs (Baillie et al., 1994; Stephenson and Cadman, 1994; Willis, 1988).

\section{Method}

- Electrofacies Analysis

Reading (1978) introduced the most widely used definition of facies, which is described as 'a distinctive rock that was formed under certain conditions of sedimentation reflecting a particular process or environment'.

Facies has been defined as a distinctive rock formed under specific geological conditions that reflect a particular process or deposition environment (Reading 1986). As different well logs respond to changes of properties of this rock, the same concept can be applied on this case as the concept of Electrofacies.

In order to obtain unsupervised facies model a reference well was selected, and a multi-dimensional dot-pattern recognition method, Multi-Resolution Graph-Based Clustering (MRGC) was successfully applied.

This clustering method characterizes each depth by calculating two different indexes aimed to describe the relationship of each data point on a multi-dimensional space with its neighbors: a Neighboring Index (NI) and a Kernal Representative Index (KRI). The first one is related to the local density of the data; while the second represents the local mode of probability function (Ye and Rabiller, 2000).

On Figure 2, a simple example of how the MRGC methods allows recognizing the limits of the different attraction groups. Despite only two dimensions are shown on this example (Gamma Ray vs Resistivity), the same concepts would be applied on as many input logs (or data in general) is used on the clustering.

Both indexes allows ranking the data to form small groups of data that may differ significantly in size, shape, and on density of data. These small groups can then be progressively merged into actual "Electrofacies" or higher scale groups, by controlling the level of detail required (Ye and Rabiller, 2000).

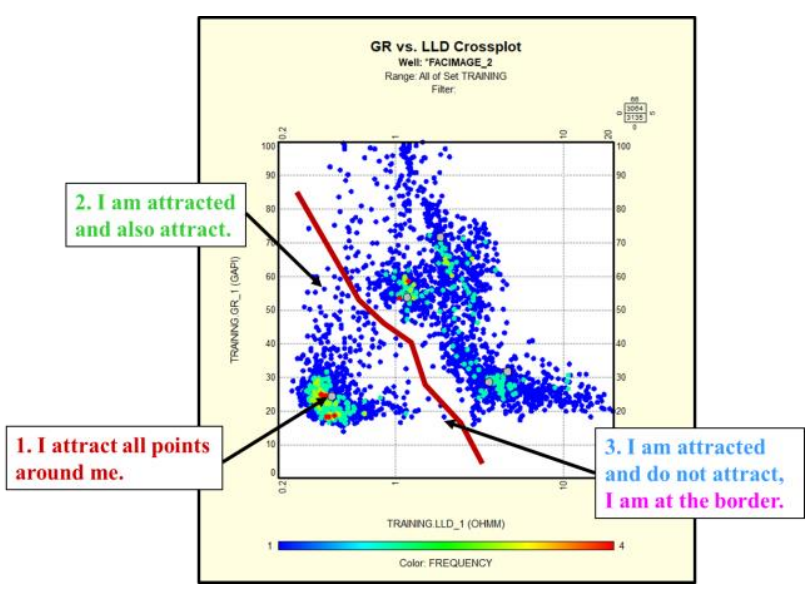

Figure 2 - Graphical example of MRGC clustering.

For this analysis a Gamma Ray, Density, Compressional Slowness and Resistivity logs were selected (Figure 3), as they were deemed as directly comparable to the Neural Network seismic inversion applied.

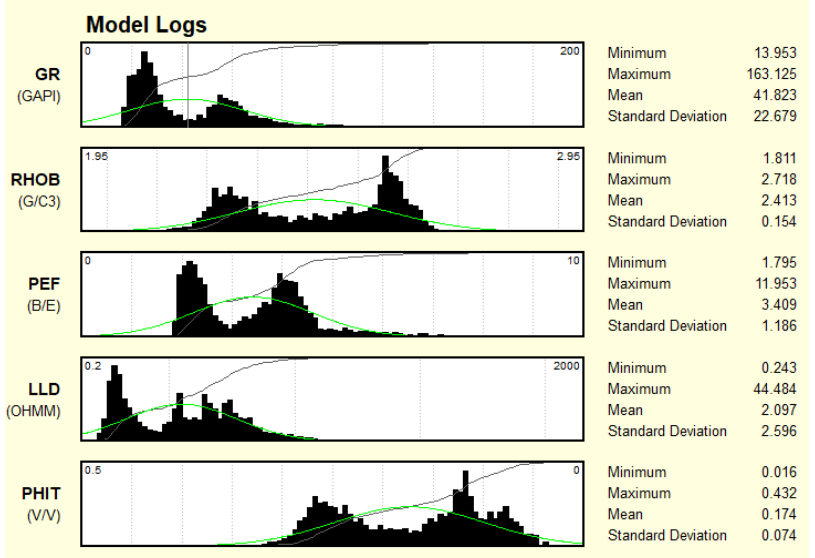

Figure 3 - Logs used to train the Electrofacies model.

- Seismic Sequence Stratigraphy

We adapted standard sequence stratigraphic analysis methods, including reflector geometries, stratal terminations, nomenclature, and hierarchical orders (Catuneanu et al., 2009; Mitchum et al. 1977; Mitchum and Van Wagoner, 1991) to identify depositional sequences on the study area.

\section{- Neural Network seismic inversion}

Neural network is applied to the selected seismic data to obtain a pseudo GR and Resistivity log volumes. We overlay this two log volumes to see the vertical distribution. With this approach has the following advantages of Neural Network seismic inversion, it can be used to predict distribution of hydrocarbon base on well log property on vertical and lateral distribution base on seismic volume, there is a relationship between the seismic attributes and the desired log properties. GR and Resistivity log volumes expected to be correlated in some sense with the seismic data. 


\section{Results}

Applying a MRGC clustering on the reference well resulted on 10 different unsupervised Facies models, ranging from 5 to 34 Electrofacies respectively. The one with 12 Electrofacies was selected as a starting point, to be up-scaled and compared directly with the results obtained from the Inversion.

Figure 4 shows the typical log responses for the Electrofacies identified. Facies 1 to 3 correspond with cleaner lithologies, with higher porosities, corresponding with potential reservoir rocks. Facies 4 to 6 show a wider range of clay content and significantly lower porosities, being regarded as non-reservoir rocks. Finally Facies 5 to 12 correspond mostly with high shale content facies.

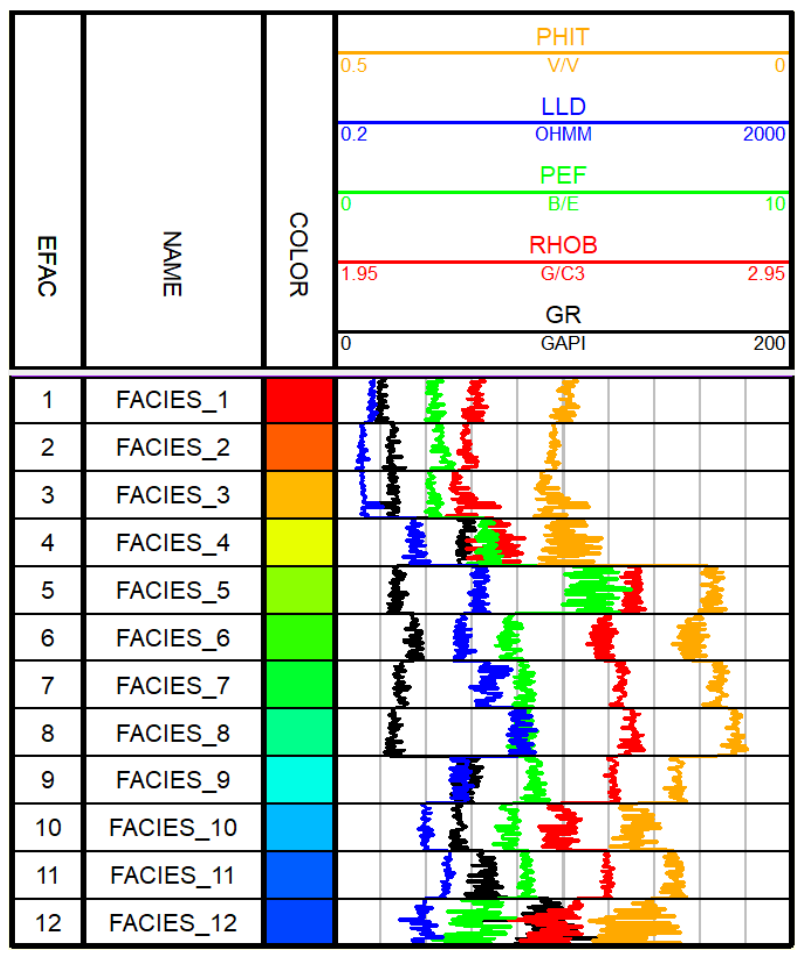

Figure 4 - Electrofacies summary.

When applying this facies model to the reference well, it is possible to recognize the main facies changes (Figure 5) to be propagated on this workflow.

Based on the seismic sequence stratigraphy analysis performed, it was possible to recognized different reflector configurations, including parallel, divergent, oblique, sigmoidal and chaotic (Figure 6). Seismic Stratigraphy accommodates subdividing the succession by architectural variations. Within the focus area, stratal terminations define seismic surfaces that could be correlated confidently across the study area.

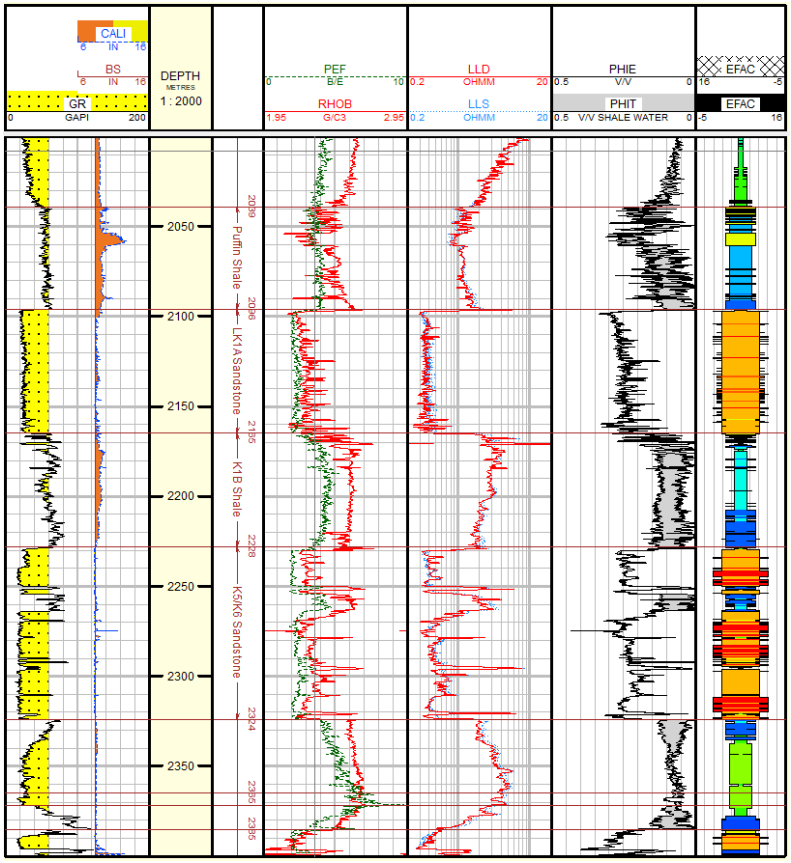

Figure 5 - Electrofacies recognized on the reference well.

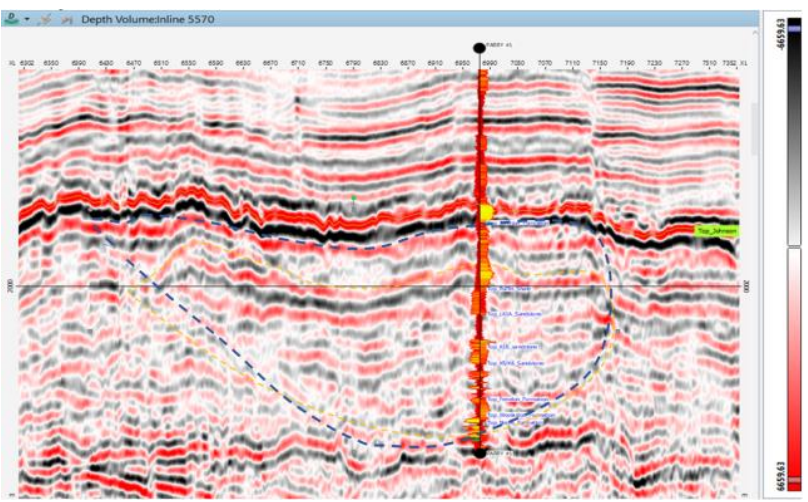

Figure 6 - Seismic section.

We interpret these reflectors as stacked slope channels (Figure 6). In 3D seismic horizon slices, we identified channels as fluvial channel. Using spectral volumes (10 $\mathrm{hz}, 20 \mathrm{hz}, 50 \mathrm{hz}$ ), seismic coherence and thin bed indicator attribute, in combination with an adjustable RGB blending in the seismic interpretation software, it was possible to highlight these geometries, allowing to easily identify these channels systems (Figure 7). 


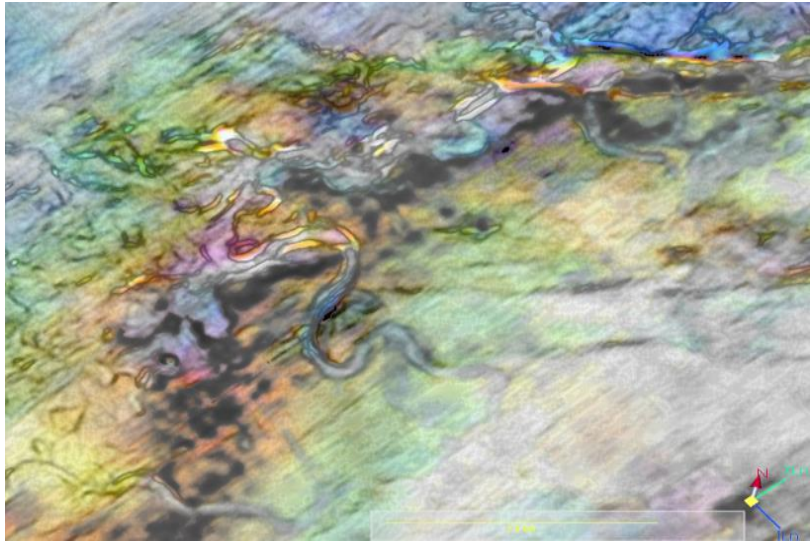

Figure 7 - Five volumes blending highlighting channel systems.

After performing the seismic inversion, a Seismic Facies log was extracted along the reference well. This Seismic Facies log allowed to validate the results of the inversion, as it was directly compared against the Electrofacies model created. This analysis was performed by using different contingency tables that allow to compare each of the Electrofacies identified on the well with the corresponding most to less likely Seismic Facies.

From the results of these contingency tables it is possible to identify a strong correspondence between both models, as the overall reconstruction is above $40 \%$ for most of the Electrofacies recognized (Table 1), despite the differences on vertical resolution. These results validate the results of the inversion at the well location, but more importantly, they are a witness of the applicability of these results on a more regional scale.

Table 1 - Contingency table showing the MRGC Electrofacies and the corresponding most to less likely Seismic Facies, displayed from top to bottom.

\begin{tabular}{|c|c|c|c|c|c|c|c|c|c|c|c|}
\hline 1 & 2 & 3 & 4 & 5 & 6 & 7 & 8 & 9 & 10 & 11 & 12 \\
\hline $4(40 \%)$ & $4(36 \%)$ & $12(33 \%)$ & $13(42 \%)$ & $14(70 \%)$ & $14(77 \%)$ & $14(62 \%)$ & $14(39 \%)$ & $13(26 \%)$ & $5(35 \%)$ & $6(43 \%)$ & $5(55 \%)$ \\
\hline $12(16 \%)$ & $5(19 \%)$ & $11(19 \%)$ & $14(33 \%)$ & $13(23 \%)$ & $13(13 \%)$ & $7(11 \%)$ & $13(36 \%)$ & $5(23 \%)$ & $6(35 \%)$ & $5(35 \%)$ & $6(39 \%)$ \\
\hline $11(13 \%)$ & $6(9 \%)$ & $10(18 \%)$ & $12(18 \%)$ & $12(7 \%)$ & $12(7 \%)$ & $8(6 \%)$ & $12(11 \%)$ & $6(19 \%)$ & $7(14 \%)$ & $8(8 \%)$ & $7(2 \%)$ \\
\hline $5(9 \%)$ & $12(9 \%)$ & $13(18 \%)$ & $11(3 \%)$ & & $11(2 \%)$ & $9(5 \%)$ & $11(7 \%)$ & $9(12 \%)$ & $9(4 \%)$ & $7(6 \%)$ & $12(2 \%)$ \\
\hline $10(6 \%)$ & $11(8 \%)$ & $7(5 \%)$ & $10(3 \%)$ & & & $10(5 \%)$ & $9(3 \%)$ & $8(10 \%)$ & $8(4 \%)$ & $9(5 \%)$ & \\
\hline $8(5 \%)$ & $10(7 \%)$ & $14(5 \%)$ & $7(1 \%)$ & & & $11(4 \%)$ & $7(2 \%)$ & $7(4 \%)$ & $13(4 \%)$ & $13(3 \%)$ & \\
\hline $13(4 \%)$ & $9(5 \%)$ & $9(1 \%)$ & & & & $12(4 \%)$ & $5(1 \%)$ & $10(4 \%)$ & $10(3 \%)$ & & \\
\hline $9(3 \%)$ & $7(2 \%)$ & & & & & $13(2 \%)$ & $8(1 \%)$ & $12(2 \%)$ & $12(1 \%)$ & & \\
\hline $7(2 \%)$ & $13(2 \%)$ & & & & & & & $11(1 \%)$ & & & \\
\hline $6(1 \%)$ & & & & & & & & & & & \\
\hline
\end{tabular}

Using Neural Network volumes (GR and Resistivity log), in combination with seismic amplitude in the seismic interpretation software, highlighted geometries that aided characterize seismic units identification easily (Figure 8).

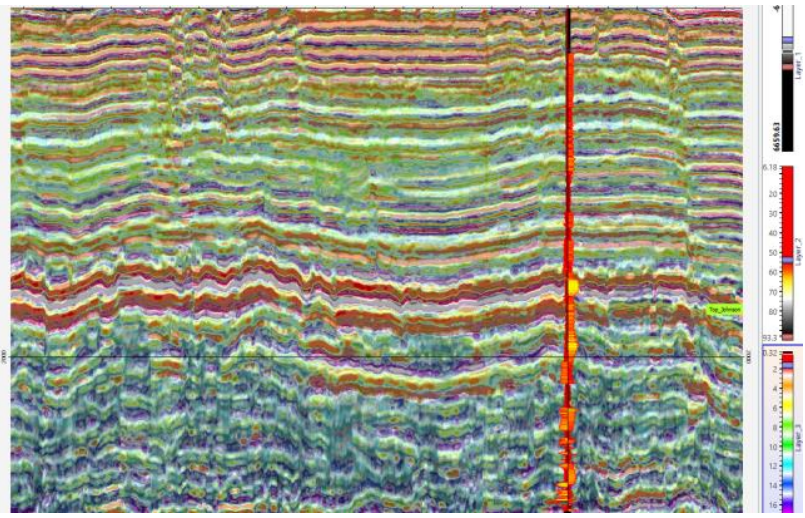

Figure 8 - Neural Network seismic inversion (seismic amplitude, GR and resistivity log volumes).

GR and resistivity log volumes we cross-plot them to see the distribution of low GR and high resistivity where the hydrocarbon exist in the field.

By using GR and Resistivity volume (Figure 9), a crossplot was made to assess the discontinuous distribution of hydrocarbons on the target zone (Figure $10)$, allowing to identify possible prospective targets with a higher degree of confidence.

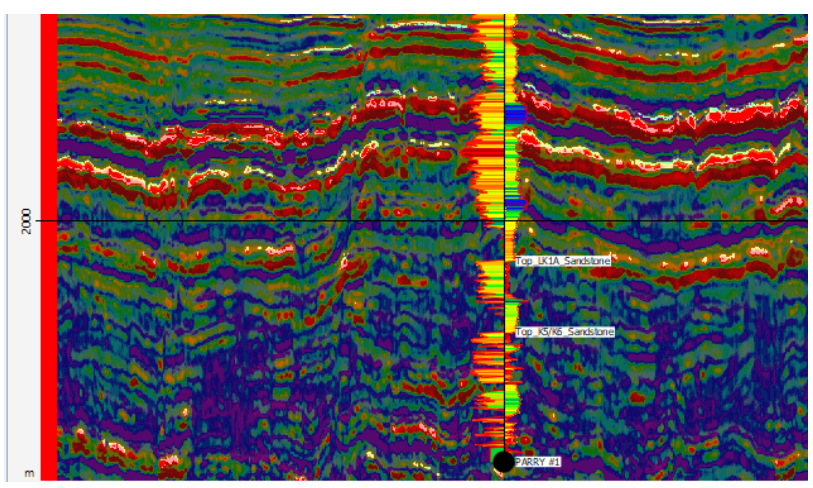

Figure 9 - GR and resistivity volumes.

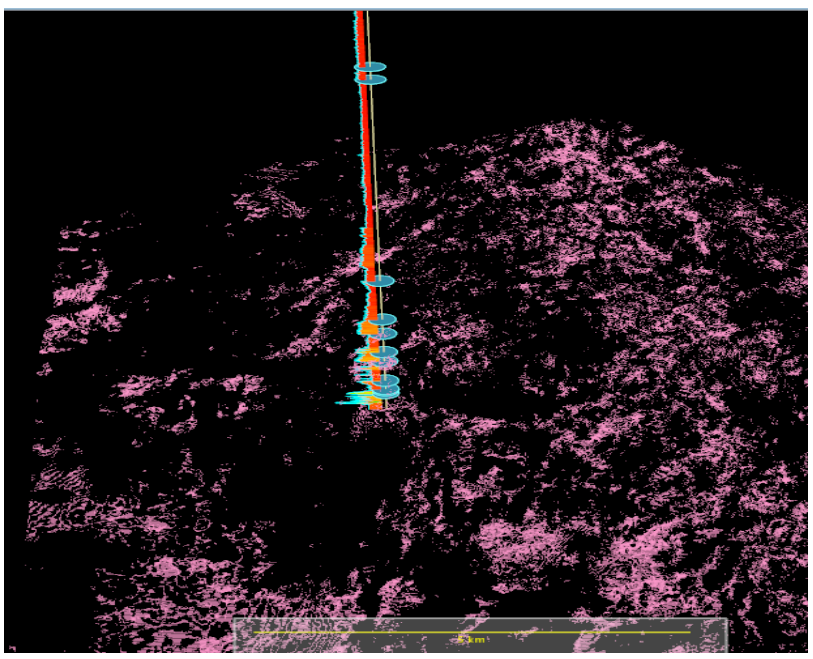

Figure 10 - Distribution from Crossploting GR and Resistivity. 


\section{Conclusions}

The workflow applied on this dataset from the Browse Basin, Western Australia, allowed drawing the following conclusions:

- Applying a Multi-Resolution Graph-Based Clustering on a reference well, allows identifying 12 different Electrofacies, that allowed easily identify possible reservoir rocks, and possible changes on it.

- Artificial Neural Networks were used to invert post-stack seismic data, to obtain petrophysical attributes.

- A high degree of correspondence was found when comparing the Seismic Facies obtained from the inversion, and the Electrofacies calculated at the reference well, witnessing the validity of this inversion as a way to identify petrophysical changes on this areas away from well control.

- Spectral decomposition of the seismic data, along with the results of the Inversion allowed to identity and delineate the channel systems with high confidence, and possible distribution of hydrocarbon.

- The results obtained may be the first step on identifying prospective targets and bypassed hydrocarbons on the Browse Basin.

\section{Acknowledgments}

The Authors wish to acknowledge Emerson Automation Solutions for providing the Paradigm software, including SeisEarth and Geolog used to take advantage of the data at hand; and Geoscience Australia for publishing the data used for this analysis.

\section{References}

PARTYKA, G. A., GRIDLEY, J. M. \& LOPEZ, J. Interpretational applications of spectral decomposition in reservoir characterization. The Leading Edge, vol. 18, No. 3, pp. $353-360,1999$.

J.P. CAStagnA, J. P., SuN, S., Seigfried, R. W. Lead. Instantaneous spectral analysis: Detection of low frequency shadows associated with hydrocarbons. The leading Edge 22, pp.120-27, 2003.

BAILLIE, P., POWELL, C. M., LI, Z., RYALL, A. The tectonic framework of Western Australia's Neoproterozoic to recent sedimentary basins. In: Purcell, P.G., Purcell, R.R. (Eds.), The Sedimentary Basins of Western Australia, Proceedings of the Petroleum Exploration Society of Australia Symposium, Perth, pp. 45-62, 1994.

REUNING, L., BACK, S., SCHULZ, H., HIRSCH, M., KUKLA, P., GROTSCH, J. Seismic Expression of Sedimentary Processes on a Carbonate Shelf and Slope System, Browse Basin, Australia, Part I, Non-tropical Carbonates, Eocene to Lower Miocene, 71st EAGE Conference \& Exhibition, Amsterdam, 2009.

ROSLEFF-SOERENSEN, B., REUNING, L., BACK, S., KUKLA, P. Seismic geomorphology and growth architecture of a Miocene barrier reef, Browse Basin, NWAustralia. Mar. Pet. Geol. 29, pp. 233-254, 2012.

MCGOWRAN, B., HOLDGATE, G. R., LI, Q., GALLAGHER, S. J. Cenozoic stratigraphic succession in southeastern Australia. Aust. J. Earth Sci. 51, pp.459496, 2004.

SAVIN, S. M., ABEL, L., BARRERA, E., HODELL, D., KENNETT, J. P., MURPHY, M., KELLER, G., KILLINGLEY, J., VINCENT, E. The evolution of Miocene surface and near-surface marine temperatures: oxygen isotopic evidence. In: KENNET, J.P. (Ed.), The Miocene Ocean: Paleoceanography and Biogeography. Geological Society of America Special Publication, pp. 49-82, 1985.

FEARY, D. A., JAMES, N. P. Cenozoic biogenic mounds and buried Miocene (?) barrier- reef on a predominantly cool-water carbonate continental-margin Eucla Basin, Western Great-Australian-Bight. Geology 23, pp. 427430, 1995.

TRIPATI, A. K., ROBERTS, C. D., EAGLE, R. A. Coupling of $\mathrm{CO} 2$ and ice sheet stability over major climate transitions of the last 20 million years. Science 326 , pp. 1394-1397, 2009.

REUNING, L., BACK, S., SCHULZ, H., HIRSCH, M., KUKLA, P., GRÖTSCH, J. Seismic expression of sedimentary processes on a carbonate shelf and slope system, Browse Basin, Australia - part I - non-tropical carbonates, Eocene to Lower Miocene. Extended Abstract In: 71st EAGE Conference \& Exhibition, 2009.

READING, H. G. Sedimentary environments and facies (2nd Ed). Oxford: Blackwell Scientific Publishing, 1986.

STEPHENSON, A. E., CADMAN, S. J. Browse Basin, Northwest Australia - the evolution, paleogeography and petroleum potential of a passive continental-margin. Palaeogeography, Palaeoclimatology, Palaeoecology. Volume 111, pp. 337-366, 1994.

WILLIS, I. Results of exploration, Browse Basin, North West Shelf, Western Australia. In: Purcell, P.G., Purcell, R.R. (Eds.), North West Shelf Symposium, Perth, W.A., Perth, pp. 253-257, 1988.

YE, S. J., RABILLER, P. A new tool for Eletrofacies analysis: Multi-Resolution Graph-Based Clustering, SPWLA, 41st Annual Logging Symposium Transaction, paper PP, 2000. 